\title{
Comparisons of Onlay versus Sublay Mesh Fixation Technique in Ventral Abdominal Wall Incisional Hernia Repair
}

\author{
Manzoor Ahmed 1 and Mukhtar Mehboob² \\ ${ }^{1}$ Department of General Surgery, Bolan University of Medical and Health Sciences, Quetta, Pakistan \\ ${ }^{2}$ Department of Surgery, Mohtarma Shaheed Benazir Bhutto Hospital, Quetta, Pakistan
}

\begin{abstract}
Objective: To compare the results of onlay with sublay mesh repair technique for ventral incisional hernia.

Study Design: Comparative study.

Place and Duration of Study: Surgical Unit IV, Sandeman (Provincial) Hospital, Quetta and Mohtarma Shaheed Benazir Bhutto Hospital, Quetta, from July 2016 to December 2017.

Methodology: Sixty-five patients, diagnosed by clinical examination as ventral incisional hernia, were included in the study. Patients were divided randomly into two groups. Group 1 had onlay mesh repair while group 2 were subjected to Sublay mesh fixation technique. Results of the procedures done in terms of operative time, wound infection, seroma formation, hospital stay, and follow-up. The data was analysed by the SPSS.

Results: The age ranges from 18-65 years, mean $39.13 \pm 11.76$ years. There were 42 males $(64.61 \%)$ and 23 females (35.4\%). The distribution of ventral incisional hernia was $42(64.61 \%)$ in midline, followed by subcostal incision in 10 $(15.38 \%)$ patients. In group 1, a total of $33(50.76 \%)$ patients underwent onlay mesh repair, while $32(49.23 \%)$ patients had underwent sublay mesh repair in group $2(p=0.007)$. The wound infection and dehiscence was less in group 2 . The seroma formation was prevalent in group1 ( $p$-value 0.005$)$. The hospital stay in group 2 was less $(p=0.003)$. The follow up for 6 months revealed no recurrence in 20 patients of group 1 and 12 patients of group 2.

Conclusion: Group 2 has a definitive edge over group 1 in the management of incisional hernia. The morbidity of the patient in group 2 was lower than group 1.
\end{abstract}

Key Words: Incisional hernia, Mesh, Onlay and sublay technique.

How to cite this article: Ahmed M, Mehboob M. Comparisons of onlay versus sublay mesh fixation technique in ventral abdominal wall incisional hernia repair. J Coll Physicians Surg Pak 2019; 29(9):819-22.

\section{INTRODUCTION}

Ventral abdominal wall incisional hernia is defined as a defect in the musculofascial layers of the abdominal wall in the region of postoperative scar. ${ }^{1}$ Ventral abdominal wall hernias (primary or incisional) are the most common operation performed worldwide. ${ }^{2}$ It is estimated that in the United States alone, 250,000 ventral hernia repairs are performed each year. ${ }^{3}$ The incidence of incisional hernia reported $2-11 \%$ and in some series $10-20 \%$ in world literature. 4,5 Surgery for incisional hernia is a big challenge for the general surgeon because of high recurrence rate, cost and morbidity. ${ }^{6}$ The open surgical treatment with prosthetic mesh (onlay technique and sublay technique). ${ }^{1,7}$ Open mesh repair is superior to suture repair but debate continues on positioning of mesh fixation. 8,9

The high recurrence rate of primary suture repair of ventral incisional hernia directed surgeons towards

Correspondence to: Surg. Dr. Manzoor Ahmed, Department of General Surgery, Bolan University of Medical and Health

Sciences, Quetta, Pakistan

E-mail: drmanzoorbaloch@gmail.com

Received: November 07, 2018; Revised: March 23, 2019; Accepted: May 30, 2019 mesh repair. There is a debate on mesh placement either onlay or sublay after strictly following the principles of incisional hernia repair, which technique is superior. ${ }^{10}$ Open incisional hernia repair with mesh are prone to developed wound complication like seroma formation and wound infection leading to increased morbidity. 11,12

This study aimed to compare the outcomes between two popular methods of mesh placement technique (onlay vs. sublay) in the patients who underwent incisional hernia repair in the local setup.

\section{METHODOLOGY}

This comparative study was conducted on patients presenting with ventral abdominal wall incisional hernia in Surgical Unit IV, Sandeman (Provincial) Hospital, Quetta and Mohtarma Shaheed Benazir Bhutto Hospital, Quetta, from July 2016 to December 2017. The sample size was calculated by taking power of study at $80 \%$ with a $5 \%$ significance level. The sample size was calculated as 33 in each group. ${ }^{13} \mathrm{~A}$ total of 65 patients who were diagnosed as a case of incisional hernia were admitted through outpatient department. The inclusion criteria were patients who were symptomatic, waiting for surgery and gave informed consent. The exclusion criteria were 
patients with previous history of chronic illness like diabetes mellitus, use of steroids and presentation with signs and symptoms of obstruction and strangulation.

Clinical history was taken and general physical, local and systemic examination was performed in all cases. Patients' fitness was ensured by hematological, sonographic and cardiac investigations.

Patients were divided randomly on alternate basis into two groups. Group 1 included those patients in whom onlay mesh fixation were performed. Group 2 included those patients in whom sublay mesh fixation were performed. In all patients, preliminary rules of incisional hernia repair was followed. In all patients, synthetic, light weight with large pores and non-absorbable mesh was used. The patients were given the same antibiotic at the time of induction of anaesthesia. The operative time for both procedures was recorded. Postoperatively patients were given same antibiotic regimen for initial three days. Clinical follow-up of both groups was performed daily to compare the initial outcome like amount of fluid in vacuum drain, wound infection, seroma formation, wound dehiscence and hospital stay. The patients were advised to do follow-up visit at 3 month and 6 month.

All the data were collected on a prescribed data sheet and results were analysed statistically by using programme SPSS version 23.0. The descriptive variables like age, gender, site and size of incisional hernia, operative time, wound infection, seroma formation, wound dehiscence and hospital stay, frequency distribution, and percentage were recorded in both groups. The significance of different variable group were determined by applying Chi-square test and calculating $p$-value; $p<0.05$ was considered significant.

\section{RESULTS}

The age ranged from $18-65$ years, mean $39.13 \pm 11.76$ years. There were 42 males $(64.61 \%)$ and 23 females $(35.4 \%)$. The male to female ratio was $1.8: 1$. For the descriptive purpose patients were divided into two groups. The group 1 comprises of $33(50.76 \%)$ patients who underwent onlay hernia mesh repair and group 2 had $32(49.23 \%)$ patients who underwent sublay hernia mesh repair. One patient from group 2 refused to participate after surgery. Majority of the patients, 56 $(86.15 \%)$ were below the age of 50 years. The age and gender had no significance with the type of hernia repair procedure ( $p=0.527$ and 0.492 , respectively). Midline ventral anterior abdominal wall incisional hernia was most common $(42,64.61 \%)$ followed by subcostal incisional hernia $(10,15.38 \%)$. Majority of the male patients $(36,55.38 \%)$ had midline incisional hernia. The size of hernial defect was more than $5 \mathrm{~cm}$ in $47(72.30 \%)$ patients. The hernial defect of more than $5 \mathrm{~cm}$ was more common in males $(38,58.46 \%)$ than in females $(14$, $21.5 \%, p=0.018)$ (Table I).
Table I: Patients profile presented with incisional hernia

\begin{tabular}{|c|c|c|c|}
\hline Variables & $\begin{array}{l}\text { Group } 1 \\
\text { (Onlay) }\end{array}$ & $\begin{array}{c}\text { Group } 11 \\
\text { (Sublay) }\end{array}$ & $p$-value \\
\hline \multicolumn{4}{|l|}{ Age of patients } \\
\hline $10-30$ years & $11(16.92 \%)$ & $10(15.38 \%)$ & 0.525 \\
\hline $31-50$ years & $19(29.23 \%)$ & $16(24.61 \%)$ & \\
\hline $51-70$ years & $3(4.61 \%)$ & $6(9.23 \%)$ & \\
\hline \multicolumn{4}{|l|}{ Gender } \\
\hline Male & $20(30.76 \%)$ & $22(33.84 \%)$ & 0.492 \\
\hline Female & $13(20 \%)$ & $10(15.38 \%)$ & \\
\hline \multicolumn{4}{|c|}{ Site of incision of hernia } \\
\hline Midline & $18(27.69 \%)$ & $24(36.92 \%)$ & 0.100 \\
\hline Subcostal & $6(9.23 \%)$ & $4(6.15 \%)$ & \\
\hline Pfinnenstiel & $4(6.15 \%)$ & $4(6.15 \%)$ & \\
\hline Grid iron & $5(7.69 \%)$ & 0 & \\
\hline \multicolumn{4}{|c|}{ Size of hernial defect } \\
\hline $3-5 \mathrm{~cm}$ & $10(15.38 \%)$ & $3(4.61 \%)$ & 0.162 \\
\hline $6-10 \mathrm{~cm}$ & $10(15.38 \%)$ & $15(23.07 \%)$ & \\
\hline $11-15 \mathrm{~cm}$ & $10(15.38 \%)$ & $12(18.46 \%)$ & \\
\hline$>15 \mathrm{~cm}$ & $3(4.61 \%)$ & $2(3.07 \%)$ & \\
\hline
\end{tabular}

Table II: Outcome variable comparison of onlay vs sublay hernia mesh repair.

\begin{tabular}{|c|c|c|c|}
\hline Variables & $\begin{array}{l}\text { Group } 1 \\
\text { (Onlay) }\end{array}$ & $\begin{array}{l}\text { Group } 11 \\
\text { (Sublay) }\end{array}$ & $p$-value \\
\hline \multicolumn{4}{|c|}{ Operative time } \\
\hline$<60 \min$ & $10(15.38 \%)$ & $4(6.15 \%)$ & 0.007 \\
\hline $60-90 \mathrm{~min}$ & 15 (23.07\%) & $8(12.30 \%)$ & \\
\hline$>90 \mathrm{~min}$ & $8(12.30 \%$ & $20(30.76 \%)$ & \\
\hline \multicolumn{4}{|c|}{ Wound Infection } \\
\hline Yes & $6(9.23 \%)$ & $3(4.61 \%)$ & 0.304 \\
\hline No & 27 (41.53\%) & $29(44.61 \%)$ & \\
\hline \multicolumn{4}{|c|}{ Seroma formation } \\
\hline Yes & $13(20 \%)$ & $3(4.61 \%)$ & 0.005 \\
\hline No & $20(30.76 \%)$ & $29(44.61 \%)$ & \\
\hline \multicolumn{4}{|c|}{ Wound dehiscence } \\
\hline Yes & $2(3.07 \%)$ & 0 & 0.157 \\
\hline No & $31(47.69 \%)$ & 32 (49.23\%) & \\
\hline \multicolumn{4}{|l|}{ Hospital stay } \\
\hline$<4$ Days & $13(20 \%)$ & $26(40 \%)$ & 0.003 \\
\hline 5-8 Days & $14(21.53 \%)$ & $4(6.15 \%)$ & \\
\hline >8 Days & $6(9.23 \%)$ & $2(3.07 \%)$ & \\
\hline
\end{tabular}

The recorded operative time in group1 was less than 90 minutes in 25 (38.45\%); while in group 2, 20 (30.76\%) required more than 90 minutes. The operative time was different in onlay mesh fixation compared to sublay mesh fixation, was found to be significant $(p=0.007)$. The time taken for male patients was more as compared to the female patients. The wound infection was more frequent in group 1 patients $(6,9.23 \%)$ as compared to group 2 patients $(3,4.61 \%, p=0.304)$. Seroma formation in group 1 was more common $(13,20 \%)$ as compared to group $2(3,4.61 \%)$ patients. Wound dehiscence was present only in $2(3.07 \%)$ patients of group 1 . Majority of the patients $26(40 \%)$ in group 2 were discharged from hospital on $4^{\text {th }}$ postoperative day followed by $4(6.15 \%)$ patients on $5^{\text {th }}$ to $8^{\text {th }}$ postoperative day, while $14(21.53 \%)$ patients of group 1 were discharged from hospital on 5th to 8 th postoperative day followed by $13(20 \%)$ patients 
on $4^{\text {th }}$ postoperative day. The hospital stay was found significant $(p=0.003$, Table II). There was no recurrence of hernia in 20 patients of group1 and 12 patients of group 2 on a follow-up of six months. The remaining patients did not come for follow-up.

\section{DISCUSSION}

Incisional hernia is reported in $10-15 \%$ of laparotomy incisions and $1-5 \%$ of laparoscopic port-site incisions. ${ }^{1}$ Strict restriction to observe the principles of incisional hernia repair lessen the postoperative complication and reduces the recurrence rate. 4 The introduction of prosthetic mesh revolutionise the repair of almost all ventral hernia defects including incisional hernias. The mesh fixation technique became the gold standard procedure for incisional hernia in late 90's. ${ }^{11}$

The golden rules before the placement of mesh were the rigorous aseptic technique, repair of the whole previous surgical scar, repair must be tension-free, sutures should be $1 \mathrm{~cm}$ deep and $1 \mathrm{~cm}$ apart and suture length $v s$ wound length must be 4:1 (Jenkin's rule). The mesh must be large enough to ensure a $5 \mathrm{~cm}$ overlap of the underlying fascial defect in all directions. The judicious use of antibiotics is mandatory for prophylaxis of infection.

In a study conducted by $\mathrm{Naz}$ et al. on comparative evaluation of sublay versus onlay mesh repair for ventral hernia, the mean age of patients in group $A$ was 40.30 \pm 4.52 years, and $39.12 \pm 4.58$ years in group $B$. There were $45(45 \%)$ males and $55(55 \%)$ females. ${ }^{14}$ In another study conducted by Kumar et al., the average age of presentation in this study was 49 years. It was more commonly in women $(n=76,84.44 \%)$ when compared to males $(n=14,15.55 \%) .15$ In this study, the overall age range from 18-65 years, mean $39.13 \pm 11.76$ years. There were 42 males $(64.61 \%)$ and 23 females $(35.4 \%)$. The male to female ratio was 1.8:1. The male predominance is due to high rate of emergency laparotomy due to trauma, while in Kumar et al. study the incisional hernia was due to obstetric or gynecological procedures. ${ }^{15}$ In many studies, the most common site of incisional hernia was midline due to worldwide increase incidence of laparotomy. In this study, midline ventral anterior abdominal wall incisional hernia was most common 42 (64.61\%) followed by subcostal incision 10 (15.38\%). There was a wide variation in size of hernial defect. ${ }^{1}$ In the study by Kumar et al., the size of the defect was assessed clinically to range from 3 to $12 \mathrm{~cm} .15 \mathrm{In}$ this study, the hernial defect of more than $5 \mathrm{~cm}$ was common in males than females. The most probable explanation was more common midline incision in male patients.

In the study by Saber et al., the mean operative time for onlay repair was $67.04 \pm 13.19$ minutes, while in sublay group, was $93.26 \pm 24.94$ minutes ranged 60 to 140 minutes. As for the drainage time, the mean total time in days was $7.47 \pm 1.7$ days in onlay repair while in sublay group was $4.5 \pm 1.1$ days. ${ }^{13}$ In a study by Ali et al., the mean operative time in onlay mesh group was 49.35 \pm 8.29 minutes, while in sublay mesh group was 63.15 \pm 15.0 minutes $(p<0.001) .16$ In this study, the operative time in group 1 in most patients $25(38.45 \%)$ was less than 90 minutes, while in group 2 most patients 20 $(30.76 \%)$ taken more than 90 minutes.

In the same study by Saber et al., seroma formation after suction drain removal was observed in $6 \%$ patients in onlay mesh repair and in $2 \%$ in sublay mesh repair. Purulent wound infection was observed in $8 \%$ onlay repair, while $4 \%$ patients in sublay repair. ${ }^{13}$ The study by Kumar et al. revealed that the wound infection was more in onlay (13.33\%) compared to underlay repair (11.11\%). ${ }^{15}$ Shahryar et al. reported $17 \%$ and $8 \%$ infection rate in onlay and sublay mesh repair, respectively. 17 In this study, the seroma formation in group 1 was more common in $13(20 \%)$ patients as compared to group 2 in $3(4.61 \%)$ patients $(p=0.005)$. Wound infection was also more in group 1 patients $6(9.23 \%)$ as compare to group 2 patients $3(4.61 \%)(p=0.304)$. In a study by Saeed et al., the wound infection was higher in sublay mesh repair. 18

In a study by Ibrahim et al., mean duration of hospital stay in the onlay group ranged from 3 to $9(4.63 \pm 0.35)$ days, whereas it was 1-4 (2.62 \pm 0.74$)$ days in the sublay group $(p=0.063) .{ }^{19}$ In this study, most of the 26 patients in group 2 stay less than 4 days followed by 4 patients on 5th to 8th postoperative day, while 14 patients of group 1 was discharged from hospital on 5th to 8th postoperative day followed by 13 patients on the 4th postoperative day $(p=0.003)$.

In the study by Kumar et al., the recurrence rate was $10.8 \%$ in onlay mesh repair, while $9 \%$ in sublay group in reported patients. ${ }^{15}$ Shaheryar et al. found a recurrence rate in onlay repair was $8 \%$, while in sublay repair was $3 \% .{ }^{17}$ Memon et al. concluded that sub-lay mesh technique is a gold standard technique for ventral abdominal wall hernias. ${ }^{20}$ In this study, there was no recurrence of hernia reported in 20 patients of group1 and 12 patients of group 2 who came to follow-up.

\section{CONCLUSION}

Sublay mesh repair has a definitive edge over onlay mesh repair in the management of incisional hernia. The operative time, postoperative complication like seroma formation and hospital stay were found significant. The morbidity of the patient treated by sublay mesh fixation technique was lower as compared to those treated with onlay mesh fixation technique.

\section{ETHICAL APPROVAL:}

Approval for conducting the study has been taken from 
hospitals administration and heads of Units before commencement of study.

\section{PATIENTS CONSENT:}

During the counselling, all patients were informed about the study, the two groups will be compared and the results/ outcomes will be published in medical journal.

\section{CONFLICT OF INTEREST:}

Authors declared no conflict of interest.

\section{AUTHORS' CONTRIBUTION:}

MA: Concept, data collection, manuscript writing , data analysis and reference collection.

MM: Concept, data collection, manuscript writing and data analysis. Final review and approval.

\section{REFERENCES}

1. Tulloh B, Nixon SJ. Abdominal wall, hernia and umbilicus. In: Williams NS, Connell PR, Mc Caskie AW. Bailey \& Love's Short Practice of Surgery: Ed 27 th CRC Press, Taylor \& Francis Group 2018: 1039-41.

2. Malik AM. Laparoscopic versus open repair of para-umbilical hernia. It is good alternative. Pak J Med Assoc 2015; 65:865-8.

3. Breuing K, Butler CE, Ferzoco S, Franz M, Hultman CS, Kilbridge JF, et al. Incisional ventral hernias: Review of the literature and recommendations regarding the grading and technique of repair. Surgery 2010; 148:544-58.

4. Sevine B, Okus A, Sarden AY, Aksoy N, Karahan O. Randomized prospective comparison of long term results of onlay and sublay mesh repair technique for incisional hernia. Turk J Surg 2018: 34:17-20.

5. Shahida PA, Rameez AS, Akram R. Complication of onlay and sublay mesh plasty in ventral abdominal hernia repair. J Surg Pak (Intern) 2015; 20:48-51.

6. Leithy M, Loulah M, Greida HA, Baker FA, Hayes AM. Sublay hernioplasty versus onlay hernioplasty in incisional hernia in diabetic patients. Menoufia Med J 2014; 27:353-8.

7. Jeremy A, Cobb IV W, Corbonell AM. Modern management of abdominal wall hernias. GHS proc 2016; 1:38-46.
8. Mommers $\mathrm{EHH}$, Leendres BJM, Leclercq WKG, dVries Reilingh TS, Charbon JA. A modified chevrel technique for ventral hernia repair: Long term results of single centre cohort. Hernia 2017; 21:591-600.

9. Baracs J, Sajjadi GS, Kelemen D, Horvath OP, Vereczkei A. Open treatment of abdominal wall hernias: Mesh repair is superior to suture repair and onlay mesh is better than sublay mesh - Five year multicentric prospective randomize clinical trial. Surgery Curr Res 2016; 6:270.

10. Timmermans L, de Goede B, von Dijk SM, Kleinrensink GJ, Jeekel J, Lange JF. Meta analyses of sublay versus onlay mesh repair in incisional hernia surgery. Am J Surg 2014; 207: 980-8.

11. Shell $\mathrm{DH}$, de La Turre J, Anradis P, Vesconez Ol. Open repair of ventral incisional hernia. Surg Clinc North Am 2008; 83:1233-4.

12. Kaya B, Uçtum $Y$, Eris $C$, Bat $O$, Ziyade $S$, Kutanis R. The surgical results of onlay mesh repair for incisional hernia. $J$ Clin Anal Med 2012; 3:425-8.

13. Saber A, Bayumi Ek. Onlay versus sublay mesh repair for ventral hernia. J Surg 2015; 4:1-4.

14. Naz A, Abid K, Syed AA, Baig NN, Umer MF, Mehdi H. Comparative evaluation of sublay versus onlay mesh repair for ventral hernia. J Pak Med Assoc 2018; 68:705-8.

15. Kumar V, Rodrigues G, Ravi C, Kumar S. A comparative analysis on various techniques of incisional hernia repair Experience from a tertiary care teaching hospital in South India. Indian J Surg 2013; 75:271-3.

16. Ali Q, Murad F, Awan TA, Khan A, Malik AZ. Onlay versus sublay technique of repairing ventral abdominal hernia. JRMC 2013; 17:192-4.

17. Shehyar HA, Shahka MA, Javeed MU. Comparisons of sublay versus onlay mesh technique of hernia repair. PJMHS 2018; 12:57-9.

18. Saeed N, Iqbal SA, Shaikh BA, Baqai F. Comparison between onlay and sublay methods of mesh repair of incisional hernia. J Post Med Inst 2014; 28:400-3.

19. Ibrahim AH, El-Gammal AS, Heikal MMM. Comparative study between 'onlay' and 'sublay' hernioplasty in the treatment of uncomplicated ventral hernia. Menoufia Med J 2015; 28:11-6.

20. Memon MR, Shaikh AA, Memon SR, Jamro B. Results of Stoppa's sublay mesh repair in incisional \& ventral hernias. J Pak Med Assoc 2010; 60:798-801. 